\title{
People in Recovery from Substance Use Disorders: What Motivates Them to Enter Addiction Treatment Agencies as Counselors?
}

\author{
Azahah Abu Hassan Shaari \\ Department of Human Sciences, Faculty of Language Studies and Human Development, Universiti Malaysia \\ Kelantan, 16300 Bachok, Kelantan, Malaysia
}

\begin{abstract}
This qualitative study aimed to understand the motivations of people recovering from substance use disorders (SUDs) to work in addiction treatment agencies as counselors. A purposive and snowball sampling technique was used to recruit 18 recovering counselors from Long Island, New York. Most of the participants self-identified as Caucasian, and a third identified as African American. All interviews were audio-recorded and transcribed verbatim. The results indicate that want to give back, perceived self-efficacy to work with SUD clients, and previous experiences with addiction treatment services motivated people in recovery from SUD to become counselors. The respondents also reported the role of intrinsic rewards, such as witnessing clients' progress over time and the opportunity to sustain their recovery, which influenced their decision to continue working in the addiction treatment field. Understanding work motivations has significant implications for assessing the staffing needs and professional development of SUD treatment programs, including recruitment, retention, and the overall size and capacity of the addiction treatment workforce.
\end{abstract}

Keywords: Addiction, counselors, motivations, qualitative, recovery, substance use disorders, SUD

ARTICLE INFO

Article history:

Received: 10 May 2021

Accepted: 10 September 2021

Published: 03 December 2021

DOI: https://doi.org/10.47836/pjssh.29.4.12

E-mail address:

azahah.ah@umk.edu.my

\section{INTRODUCTION}

This qualitative study aimed to understand the motivations of people recovering from substance use disorders (SUDs) to work in addiction treatment agencies as counselors. Addiction to alcohol and drugs has long been recognized as a chronic disease and is the leading cause of morbidity and mortality in the United States (Prom-Wormley et al., 
2017; Ruhm, 2018). Fatal drug overdose rates increased from $6.1 \%$ deaths in 1997 to $21.7 \%$ in 2017 - an increase of $250 \%$ (Ruhm, 2018). From 1999 to 2016, a total of 351,630 U.S. residents died from opioidrelated causes (Kiang et al., 2019), and 33,091 opioid overdose cases were reported in 2015 (Madras, 2017). Furthermore, Monnat et al. (2019) reported high drug mortality rates and higher rates of opioid prescription in counties with economic disadvantages. In 2018, the Substance Abuse and Mental Health Services Administration (SAMSHA) revealed that 23.02 million adults aged 18 or older had a SUD. Among them, 14.06 million (75.2\%) struggled with alcohol use, 6.81 million (36.4\%) struggled with illicit drugs, and 2.15 million (11.5\%) struggled with both illicit drugs and alcohol. Despite the growing crisis of SUDs, a systematic review of 415 scientific studies of recovery outcomes by Kelly et al. (2019) indicated the number of individuals who reported having resolved a SUD ranged from $5.3 \%$ to $15.3 \%$.

The SUD treatment workforce plays a significant role in facilitating effective prevention and treatment. This workforce of practitioners includes counselors, medical professionals, and social workers who provide treatment to SUD clients (Bouchery \& Dey, 2018). The National Survey of Substance Abuse Treatment Services reported that 197,559 counselors were employed in SUD treatment agencies (SAMSHA, 2018). Historically, counselors with SUD history who have maintained recovery have dominated the addiction treatment field (Nurse, 2020). Although precise data are lacking, researchers have estimated that approximately $40 \%-70 \%$ of people in recovery from SUD work in addiction treatment agencies as counselors (Fialk, 2018; Simons et al., 2017). Despite these high percentages, few qualitative studies have explored counselor's motivations, specifically those in recovery from SUD who decided to work in addiction treatment.

Even with the significant percentage of counselors in recovery from SUDs working in the addiction treatment field, studies related to people's motivation in recovery from SUD working in the field are still limited (Fialk, 2018; Shannon, 2017). Instead, existing studies on motivation and career determinants have mostly focused on counselors without a history of SUD entering the counseling profession (Cheung, 2016; Corey \& Corey, 2020; Hill et al., 2013; Kaslow, 2005; Mahrer, 2005; McCullough, 2000; Norcross \& Farber, 2005; Orlinsky \& Rønnestad, 2005; Poon et al., 2020). Findings from these studies have identified several motivations of individuals to enter the service field as counselors, including the desire to help others overcome stressful situations (McCullough, 2000), the influence from supportive mentors (Mahrer, 2005; Norcross \& Farber, 2005), personal characteristics that fit the helping profession (Kaslow, 2005; McCullough, 2000; Orlinsky \& Rønnestad, 2005), personal experiences with therapy (Linington, 2016), and anticipated career satisfaction from the profession such as enhanced 
feelings of self-value and improvements in psychosocial adjustment (Mahrer, 2005). According to Norcross and Farber (2005), a common first impetus behind many helping professionals entering the field is wanting to help others - a conscious, socially desirable, and professionally acceptable career determinant.

Other recent studies by Cheung (2016), Corey and Corey (2020), Danes (2016), and Poon et al. (2020) reported the intention to help others as a common motivation for becoming a counselor. For example, Corey and Corey (2020) listed eight types of motivation for becoming a counselor, including making an impact and caring for others. Likewise, Poon et al. (2020) reported social contribution as motivation for choosing a counselor as a profession. Further, Cheung (2016) found four significant motivations for becoming a counselor: wanting to help others, having previous experiences with counseling, achieving life stability, and having expertise in the counseling field. Similarly, Hill et al. (2013) reported wanting to help others, perceived counseling skills, and competency as motivations for becoming a counselor.

Another motivation is related to the role of chance encounters that shape people's lives, for example, an inadvertent meeting with someone who later becomes a valued mentor or role model, or a moment that could propel or shape one's direction in life, including career choice (Brown, 2017; Chien, 2020; Foss-Kelly \& Protivnak, 2017). Brown (2017) and Foss-Kelly and Protivnak (2017) reported that a supportive relationship with a mentor helps create positive experiences among graduate students pursuing careers in the counseling field. Rønnestad and Skovholt (2003) examined the role of mentors who could portray curiosity, encourage learning, and postulate intellectual conversation. Expectations regarding the rewards of becoming a therapist, including intellectual stimulation and self-growth, have been reported by many as their greatest influences for entering the counseling field (Bilgin, 2015; McMillan et al., 2016; Renard \& Snelgar, 2016). Bilgin (2015) also reported that the work values of sense of achievement and independence motivate students to pursue careers in counseling. Financial rewards also may serve as encouragement for those who want to pursue counseling as their career (McMillan et al., 2016). Farber et al. (2005) concluded that a helping profession that allows people to feel agentic and communal, have an enhanced sense of identity and intimacy, and work in the service of themselves and others serves as powerful motivation to work in this field. Other researchers (Farber et al., 2005; Stevanovic \& Rupert, 2004) have revealed that individuals' motivation to become therapists is related to anticipated career satisfaction, especially when they can help others in trouble and develop a meaningful relationship with clients.

However, studies pertaining to people in recovery from SUD who enter the addiction treatment field as counselors are limited and outdated. Ottenberg (1977) found that those in recovery from SUD decided to enter the addiction treatment field because of their familiarity with and 
understanding of addiction issues, including the challenges of avoiding relapse and the complexities of sustaining recovery. A more recent study by Doukas and Cullen (2010) identified that key factors such as the desire to help other SUD clients overcome their drug dependency and give back to the community-served as motivators for people in recovery to become counselors in the addiction treatment field. In addition, Shannon (2017) reported wanting to help SUD users overcome their dependency and wanting to give back to the community as motivations for recovering practitioners to work in addiction counseling and strengthen their recovery. Nielson (2016) reported that counselors' recovery strengthened when they could give back by helping others. Previous experiences with substance abuse and knowledge related to the devastating impact of addiction led counselors in recovery to become passionate about and dedicated to helping others (Doukas, 2015). In addition, personal characteristics like empathy, positive attitude, and compassion were identified as reasons for those in recovery to work in the addiction treatment field (Nurse, 2020).

The present work is among the first qualitative studies to explore the motivations of individuals in recovery from a SUD to work as counselors in the substance use treatment field. In addition, this qualitative research study aims to explore the experiences of recovering counselors, specifically those working in the addiction treatment field, using a narrative inquiry method.

\section{LITERATURE REVIEW}

\section{Recovery from SUD}

According to the Diagnostic and Statistical Manual of Mental Disorders-5, SUD encompasses the excessive use of 10 different drugs, including alcohol, cannabis, opioids, sedatives, hypnotics, and anxiolytics (American Psychiatric Association, 2013). SUD is characterized by the presence of a cluster of cognitive, behavioral, and physiological symptoms, including taking substances in larger amounts or over a longer period than was originally intended and continuing to use substances despite them causing recurrent interpersonal problems and craving or having an intense urge to use drugs (American Psychiatric Association, 2013). Several studies have investigated the factors contributing to SUD recoveries (DuPont et al., 2015; Goodman et al., 2020), such as readiness and motivation to stop using drugs, social support, and social capital (Best et al., 2016). Moreover, factors such an active engagement in the community and support from spouse or family members will lead to a better quality of life and the ability to maintain recovery (Gueta et al., 2020; Raynor et al., 2017). In addition, the use of a social network such as peer support or self-help group (Bathish et al., 2017; Best et al., 2016, 2018; Bliuc et al., 2017) is crucial to sustaining SUD recovery. Research has also indicated different types of therapies available to help individuals in SUD recovery, such as dialectical behavior therapy (Linehan \& Wilks, 2015) and methadone maintenance treatment (Calcaterra et al., 2019; Fei et al., 
2016). In addition to studies on contributing factors and therapies, there are empirical studies on the use of specific models, such as the Acculturation Model that was developed based on the ecological framework, the Addicted-Self Model, the Social Model, the Medical Model, Disease Model (Volkow et al., 2016), and the Transtheoretical Model (Dugdale et al., 2016), which helps guide SUD counselors to understand the influence of environment and culture on SUD recovery.

\section{Recovering SUD Counselors}

The employment of individuals recovering from SUD as counselors originated among 12-step-program members who had become sober and wanted to help others (Nielson, 2016; White, 2006). The 12-step model that emphasized sharing SUD recovery stories with other group members was introduced by William "Bill" Griffith Wilson in 1935 (White, 2006). Studies related to using the 12 -step program found that participation created a sense of belonging, increased feelings of self-value, and reinforced strategies to sustain recovery (Dermatis \& Galanter, 2016). Furthermore, 12-step group members perceived helping others as personally empowering, rewarding, and therapeutic (von Greiff \& Skogens, 2021). In addition, interpersonal rewards for supporting and helping other people recover from SUD increased recovery lengths of (Beraldo et al., 2019; Chick, 2015) and led to significant improvements in psychosocial adjustment and social competence (DeLucia et al., 2015).
In addition, recovering SUD counselors face multiple challenges during their work with substance-abuse clients, including burnout, high risks of relapse, and unethical dual relationships due to several factors, including occupational stress, SUD histories, and psychiatric distress (Greene et al., 2019). Additionally, a lack of support and overcommitted to work have increased the chances of relapse for counselors in SUD recovery (Doukas \& Cullen, 2010; Tracy $\&$ Wallace, 2016). Finally, the development of unethical dual relationships between recovering counselors and SUD clients due to participation in the same 12-step meetings outside the agencies was highlighted as a significant past research challenge (Reamer, 2020).

Another related area that past research examined was recovering counselors' seeking and receiving social support to cope with challenges in the workplace. Participation in self-help groups (Doukas \& Cullen, 2010), recovery-focused clinical supervisions (Bathish et al., 2017; Deane et al., 2019), and in-house training on selfcare and organizational structures (Wile \& Jenkins, 2013) were found to be essential for recovering counselors to cope with jobrelated stress. However, studies found that many recovering counselors were reluctant to attend support groups and were less likely to use recovery-focused supervision because they perceived that their participation might interfere with their credibility as counselors (Robinson, 2018; Warren et al., 2011). 


\section{Theoretical Framework}

This study used self-determination theory (Deci \& Ryan, 2008) to understand people's motivations in recovery from SUD to become counselors. Based on this theory, people who have fulfilled the basic needs of competence, relatedness, and autonomy will feel inspired to pursue their life goals and work on personal development and generativity (Gaine et al., 2021). The decision to pursue life goals is based on the two types of motivations. Intrinsic motivation refers to an individual's behavior or acts influenced by their internal drive, satisfaction, or sense of fulfillment, whereas extrinsic motivation is an act or behavior driven by external rewards, including fame (Bunce, 2019). In addition, Vroom (1964) introduced expectancy theory to explain motivations and rewards regarding why people choose their occupations, the quality of their work performance, and the satisfaction or rewards they expect and derive from their work. Vroom (1964) posited that people have expectations about the outcomes or rewards of their work behaviors, and they will be motivated to choose work behaviors that will help them achieve their desired outcomes.

Self-determination and expectancy theories focus on examining human motivation to pursue desired life goals. Selfdetermination theory maintains that people are motivated to lead a meaningful life once they have achieved a sense of fulfillment, a sense of relatedness with others, and self-autonomy. Self-determination theory, in particular, is relevant to this qualitative study because it explains the human capacity to experience active growth once they overcome roadblocks - in this study, addiction. Expectancy theory also focuses on motivation. However, this theory adds that in trying to establish a better life situation, people choose specific behaviors based on their expectations about what will lead to meaningful outcomes and valuable rewards to improve their lives. In this study, people in recovery from SUD are motivated to become counselors because they expect that this career will allow them to help others while sustaining their recovery at the same time.

\section{Background and Demographics of Participants}

Sampling and Sample. Both purposive and snowball sampling techniques were used to recruit participants. These sampling strategies were used to recruit participants from a non-profit organization in Long Island, New York. As illustrated in Table 1, the sample in the current study comprised of 18 counselors recovering from SUD, the majority of whom had a Master of Arts (MA; $n=2$ ) or Master of Social Work (MSW; $n=$ 10) as their highest academic qualification and had earned professional licensingLicensed Master Social Worker (LMSW) or Licensed Clinical Social Worker (LCSW)to provide counseling services to clients. In addition, six of the 18 participants reported completing high school $(\mathrm{n}=3)$, Bachelor of Arts $(n=1)$, and Bachelor of Social Work $(n=2)$ and had achieved the status of Credentialed Alcoholism and Substance Abuse Counselor (CASAC), certifying 
Table 1

Participant demographics

\begin{tabular}{lc}
\hline Demographic trait & $\begin{array}{c}\text { Number } \\
(\mathrm{N}=18)\end{array}$ \\
\hline Gender & 6 \\
Female & 12 \\
Male & \\
Ethnicity & 10 \\
Caucasian & 6 \\
African American & 1 \\
Hispanic & 1 \\
Native American & \\
Highest level of education & 3 \\
High school & 1 \\
Bachelor of Arts (BA) & 2 \\
Bachelor of Social Work (BSW) & 2 \\
Master of Arts (MA) & 10 \\
Master of Social Work (MSW) & \\
Professional licensure / credential & 6 \\
LMSW & 6 \\
LCSW & 6 \\
CASAC & \\
Type of SUD agencies & \\
Outpatient treatment & \\
Inpatient treatment & \\
Peer-run clinic & \\
Currently attending 12-step program & \\
Nes & \\
\hline
\end{tabular}

them to work as counselors in the addiction treatment field. Of the 18 respondents, ten were Caucasian, six were African American, one was Hispanic, and one was Native American. Twelve were male, and six were female. Their ages ranged from 35 to 66, with a mean age of 53.6. The time spent in SUD recovery ranged from five to 38 years, with a mean of 22 years and five months, but most participants $(n=16)$ reported being in SUD recovery for over ten years. Twelve participants worked in the addiction treatment field for more than ten years, with tenures ranging from one to 36 years.

\section{METHODOLOGY}

\section{Study Design}

A qualitative research design provides participants with the opportunity to share their stories and use their voices and allows participants to construct their stories through their interpretation (Creswell, 2007). This study employs the research methodology of narrative inquiry to explore the motivations of people in recovery from SUD to become counselors. Because narrative inquiry views social phenomena in a broader context by focusing on the subjective meanings of participants' reality and contexts in their naturalistic settings (Clandinin \& Caine, 2013), it allows study participants to construct their stories about their motivations to become SUD counselors in addiction treatment agencies through their interpretation.

\section{Eligibility Criteria}

The sample in this study comprised counselors who had a history of SUD prior to working as counselors in addiction treatment services. The specific eligibility criteria were as follows:

1. Must be 18 years old or above and be able to understand and speak fluent English

2. Must have had a history of SUD before entering the addiction treatment field

3. Must have been in recovery from SUD for at least two years

4. Must have been working full-time for at least one year as a counselor in an addiction treatment agency 
The following individuals were excluded from the sample:

1. A counselor who had relapsed in the month preceding the interview

2. Those in recovery from nicotine and/or caffeine as their primary drug of choice

\section{Recruitment Procedures}

The purposive and snowball sampling techniques were used to recruit participants for this study for the following reasons, respectively. First, a purposive sampling strategy was used to recruit participants from a not-for-profit agency in Long Island, New York. This organization is well known for its active collaboration with other government agencies, treatment providers, and the public to support people in SUD recovery. Prior to recruitment, the researcher contacted the organization's executive director via email to explain the study, its goals, and objectives. The executive director, who was one of the participants in the sample, provided written formal permission for the researcher to attend the organization's monthly meetings and explain the goal and specific objectives of the study to the non-profit staff members. Interested individuals then contacted the researcher directly via email or phone to screen the potential participants to ensure they met the eligibility criteria. Those who met the criteria were asked to interview at their preferred time, date, and location. Second, the snowball sampling technique was used, wherein the researcher asked respondents who completed the interview to refer other individuals outside the non-profit agency who fit the inclusion criteria may be interested in participating in the study.

\section{Data Collection and Management}

The researcher collected data through one in-depth, semi-structured, face-to-face interview with each participant. Prior to the interview, each respondent was asked to complete a short sociodemographic questionnaire. On average, the interviews lasted 72 minutes, the longest being 88 minutes. The researcher used a semistructured interview protocol comprising open-ended questions to explore the motivations of recovering counselors to work in the field.

\section{Rigor and Triangulation of Data Sources}

The peer review process was employed to assess whether the findings were consistent with the data and comported with the data to verify the credibility of the findings. The researcher presented the themes and subthemes to colleagues working as counselors in the field of substance use treatment and discussed them. All counselors confirmed that the findings were consistent with their knowledge of the field and the population. Member checking was also used to assess the validity of the findings and to provide an opportunity for participants to further elaborate upon their interview (Patsiopoulos \& Buchanan, 2011). All 18 participants were contacted, and the researcher explained the member checking 
process. Of the 18 interviewees, six agreed to review the summary of subthemes and themes, and all six confirmed their accuracy. Transferability refers to the applicability of findings to other contexts (Nowell \& Albrecht, 2019) and confirmability or the neutrality of the data, where the findings of a study are shaped by the respondents and not by researchers' bias or interest. Transferability and confirmability of findings were maintained via triangulation of data. As suggested by Lietz et al. (2006), data were triangulated via 18 audio-recorded semi-structured interviews, as well as the researcher's reflective journal. Audio recording and the use of semi-structured interview techniques enabled the researcher to capture laughter, sighs, and sarcasmaural aspects that could not be capture in a transcription alone. Use of a reflective journal also allowed the researcher to make observation notes and record interviewees' concerns that were expressed outside the context of the interview. A reflective journal, which records researcher's biases, values, and perspectives, can also be used to gauge the confirmability of a study (Yao \& Vital, 2018).

\section{Data Analysis}

The researcher audio-recorded all interviews with the participants' written permission, transcribed them verbatim, and then analyzed the content based on the thematic analysis (TA) method. Braun and Clarke (2014) provided six phases of TA; familiarizing yourself with the data; generating initial codes; searching for themes; reviewing potential themes; defining and naming themes; and producing the report that allows qualitative researchers to identify the participants' answers relevant to answering a particular research question (Braun \& Clarke, 2014). First, the researcher read the interview transcripts to understand the data and start to think about the meanings or values that emerged from the participants' conversations. The researcher then listened and re-listened to the recorded interviews to analyze and determine the participants' meanings when answering the interview questions. In the next phase, the researchers categorized the transcribed information into codes or patterns based on the research questions. Finally, the researcher combined the identified themes to create in-depth stories about the motivations of people in recovery from SUD to work as counselors in addiction treatment agencies.

\section{RESULTS}

After recovering from addiction to substance use, the decision to embark upon a career as an addiction counselor was significant for all study participants. Their reasons for this decision ranged from a desire to give something back to a feeling that they possessed the skills to work with substance-using populations and their own experiences with addiction staff members. The respondents also reported the role of intrinsic rewards, such as witnessing clients' progress over time and the opportunity to sustain their recovery, which influenced their decision to continue working in the addiction treatment field. 


\section{Desire to Give Back}

The majority of respondents in this study participated in a 12-step program, a mutual aid group, where members support one another to achieve and maintain recovery from SUD. These participants described experiencing a strong desire to "give back" to others seeking treatment for addiction as their primary motivation for entering the field of addiction treatment. For most study participants, the sentiment of "giving back" to those seeking recovery stemmed from the 12-step program, which emphasizes spirituality and sharing personal recovery stories to help others find their path to recovery. As a result, they felt obligated to support those in similar need, as described in the following quotation:

"I never [would have] got to where I am now by myself. It's because somebody else from the 12-step came along and let me know that there is life after recovery. So, they tell me you can't keep recovery unless you give it away. And now, I have an opportunity to work in [an] environment, which allows me to share my story, to give them some hope. They were doing something good for me, and now it's my obligation to give back to others." (15 years in recovery, 14 years of working in [the] addiction treatment field).

A desire to give back to help those seeking SUD recovery was also influenced by the 12-step programs' philosophy of "reaching out and helping others." As a result, participants viewed giving back as an obligation to fulfill.

A third of the study participants stressed that their determination to give back emerged from their sense of gratitude toward their recovery. They expressed manifesting their appreciation for God's work in their life by becoming counselors in the addiction treatment field to help others still struggling with addiction:

"So, I know why I'm here, and I am clear about that. What motivates me to work in this field is that God gave me an ability to help people. And that is how I am connecting [with] and paying back God." (26 years in recovery, six years of working in [the] addiction treatment field).

\section{Having the Knowledge and Skills to Become a SUD Counselor}

Several respondents were pushed to think critically about the gaps in access to treatment for substance-using populations, which was the chief motivator to pursue careers as addiction counselors. One participant explained his decision:

"Growing up, I was involved in gangs, and I never had guidance because my father died when I was 16 years old. I never had somebody telling me, "No, you can't do that." I had to learn on my own. So, I felt that I needed to be part of the solution, not part of the problem. And part of the solution is to become a counselor 
and help other individuals deal with their addiction." (29 years in recovery, 20 years of working in [the] addiction treatment field).

Having gone through rigorous treatment and faced challenges to recovery and the threat of relapse, most participants strongly believed in their abilities to guide others struggling with SUD. Furthermore, they believed in their competence, skills, and insights to work as counselors helping SUD clients in the addiction treatment field. Participants' narrations also revealed that they perceived their journeys and their abilities to understand the tough battles of recovery substantively, empathize, and exhibit compassion as essential for working with SUD clients.

\section{Experiences with Addiction Staff Members}

Positive experiences with previous addiction practitioners while receiving SUD treatment also emerged as an important motivator that had inspired five study participants to enter the addiction treatment field as counselors. For these participants, their direct-care practitioners had served as role models and vital enablers of their recovery process. As the result, they ultimately became a significant motivator to pursue a similar career, as evidenced below:

"One of the counselors there, I've really admired what she's done for me, and I thought it was awesome.

She got me into a halfway house, and I ended up receiving a lot of support that I [had] never had for a long period. I learned so much from her, and I give her all the credit. I feel that kind of lit the fire for me to be here because I just learned so much from her." (12 years in recovery, two years of working in [the] addiction treatment field).

However, one participant described a negative encounter with a SUD counselor he perceived as "authoritative" in treatment. He felt the staff member negatively impacted his sense of hope that recovery was achievable. This negative experience served as a motivating factor for the participant to become a competent and empathic SUD treatment counselor, as depicted in the following quotation:

\section{"The motivating factor for me was} the way that I was treated by the counselor during treatment. The counselor yelled and screamed at me and reminded me of past life events. And it created a poor rapport between the counselor and me. So, I made a promise to myself that I wouldn't treat people the way that I was treated." (4 years of recovery, two years of working in addiction [the] treatment field).

\section{Gaining Intrinsic Rewards as a SUD Counselor}

All participants spoke about the intrinsic rewards of working as a counselor in the addiction treatment field. In addition, all participants described reaping emotional 
rewards and the happiness of witnessing their clients' progress over time, which deepened their motivation to continue working in addiction treatment agencies. The following quotation serves as an example of these feelings:

"I got to see the process and the progress of somebody who came in here. They were homeless and using [drugs]. And now, they c [a] me back, and they were all clean. So, you get to see all the work you do here and the people you help get better, you know? I mean, how could that not be a motivation?" (24 years of recovery, 22 years of working in [the] addiction treatment field).

Importantly, many participants reported that working in the SUD treatment field to assist clients with addiction issues provided them with another significant reward: sustaining their recovery. Working continuously with SUD clients, advising them, and helping them in their recovery process reinforced many of the participants' recoveries:

"I think the career anchors me in some ways because I feel like I have an obligation. This is not like another field where you could just go out and get high, and then the next day comes to work and pretend like everything is okay. That's [being] a hypocrite. I have accountability and responsibility for people. You have to practice what you preach, so to speak." (13 years in recovery, 12 years of working in [the] addiction treatment field).

Finally, many respondents stated that a significant perceived benefit was their contribution to creating better and healthier communities. Therefore, it was vital in keeping them motivated to continue their work as counselors in the substance abuse treatment field, as one respondent stated emphatically:

"It's the clients who come to the door that need[s] help: the next inmate who's being released from jail and has nowhere to go, the person who says he's committing a crime because his medication isn't working right. That gives me [the] motivation to get up every day and do the work to the best of my ability. And the work would never be done until we have no need for places like this anymore." (15 years in recovery, 14 years of working in [the] addiction treatment field).

The findings revealed that people in SUD recovery are motivated to work in the addiction treatment field because of the feeling of wanting to give back, perceived self-efficacy, and prior experiences with SUD counselors that have inspired them to pursue a career in the same field. In addition, intrinsic rewards such as witnessing their clients' progress over time while providing treatment services to SUD clients influenced their decision to stay in the field. 


\section{DISCUSSION}

The findings revealed varied motivations for individuals in recovery from SUD to work as counselors in addiction treatment. A deeply ingrained desire to give back by helping others who struggle with addiction emerged as a significant motivator for many respondents in this study. Recovering SUD counselors reported that giving back was associated with altruism and selfhealing from previous struggles with addiction, encouraging them to help others who are suffering. This finding aligns with the findings of other studies on the career determinants of entering the helping profession (Norcross \& Farber, 2005; Orlinsky \& Rønnestad, 2005). These studies reported wanting to give back as a desirable and socially and professionally conscious motivation to enter the helping profession. The study was limited to therapists without substance abuse history; however, these therapists highlighted that the profession allowed them to embrace the altruistic motive of helping others, which was a powerful motivator to enter a mental health profession (Foss-Kelly \& Protivnak, 2017; Robinson, 2018). The present study added a new perspective by looking at counselors recovering from SUD.

The findings also highlighted the intent of those in recovery to address gaps in treatment for the SUD population as motivations to work as counselors in the addiction treatment field. These gaps comprised some people's inability to receive appropriate care due to difficulties in accessing quality SUD treatment services integrated medical care, and continued support after discharge (Gueta et al., 2020). The experiences of being marginalized and disempowered former drug users inspired the participants to empower others, consistent with a study by Farber et al. (2005).

Confidence in one's ability to guide others who struggle with addiction issues was found to be another impetus for pursuing a career in the substance abuse treatment field. In addition, participants indicated that completing rigorous addiction treatment and overcoming barriers to recovery renewed their sense of self-efficacy and confidence in their work with SUD clients. This finding echoed those of many studies (DeLucia et al., 2015; DuPont et al., 2015; Linington, 2016) that reported that people who had undergone addiction treatment and achieved long-term recovery from a SUD had high self-esteem and exhibited compassion and empathy for those who still struggled with addiction.

Finally, the therapeutic relationship respondents developed with their addiction treatment counselors served as a key motivator to follow the same career path. The present study found that previous addiction counselors served as role models and provided a sense of encouragement that recovery was possible and validation that those in recovery had the skills and potential to improve their quality of life. It was consistent with the findings of other studies on the influence of mentors or role models in the helping profession (Kern, 2014; Zosky, 2013). 
Another noteworthy finding related to the motivation to pursue a career in this profession was having had negative experiences with previous SUD counselors. It aligns with prior studies that reported that, at times, unhelpful aspects influence treatment outcomes, including unskilled addiction counselors who exhibit a lack of empathy, adhere strictly to only one type of treatment, have limited knowledge regarding current drug treatments, and lack professional boundaries while treating their SUD clients (Pietkiewicz \& SkowrońskaWłoch, 2017). Respondents in the current study who had prior negative experiences were determined to provide better experiences and outcomes for their clients.

\section{CONCLUSION}

\section{Implications for Practice}

In the context of low retention rates for SUD counselors (Hatch-Maillette et al., 2019), a better understanding of the motivations of individuals for entering the addiction treatment field as counselors will improve recruitment and retention rates among SUD counselors. In this study, most participants described the want to give back and perceived self-efficacy at helping others as motivations to become counselors. This study identifies ways to recruit future SUD counselors by explaining current counselors' motivations and rationales for choosing this profession. This field must retain counselors already in the field. Identifying the rewards of SUD counselors might also encourage others to join the field regardless of their recovery status.

\section{Implications for Policy}

This study examines an important element for developing the SUD workforce: motivations for becoming a counselor. In the United States, workforce development is a key factor in providing quality SUD treatment services to SUD clients and their families (SAMSHA, 2018). Hiring qualified and skillful SUD counselors to address the severe impact of addiction nationwide must be a priority, especially when fatal overdose numbers in the United States surpassed those of motor-vehicle crashes (Tiesman et al., 2019). The present study found that perceived competency (i.e., knowledge and skills related to SUD) motivates people to become SUD counselors. Continuous communication between policymakers, stakeholders, counselors, and SUD researchers is needed to address the standardization of SUD counselors' credentials, licensing, and training, all of which have an influence on the development of SUD counselors' competency.

\section{Theoretical Implications}

The self-determination theory posited that people are active beings and can grow by exploring their sense of self (Deci \& Ryan, 2008). In the present study, selfdetermination theory was supported by respondents' decisions to work as counselors due to pursuing meaningful lives to give back and help others and to utilize their skills in and knowledge of working with the SUD population based on their prior experiences. Furthermore, the expectancy 
theory was supported by respondents' decision to work as counselors. They expected that the profession would allow them to help others and use their skills in and knowledge in working with the SUD population based on prior experiences.

\section{Recommendations for Future Research}

This qualitative research presents several possibilities for future explorations in both qualitative and quantitative studies. Future quantitative research can measure and explore associations between work motivation and other variables like treatment outcomes, rewards, and retention. Future research should also examine the motivations of recovering individuals who are not counselors, like nurses, physicians, and support staff, working in addiction treatment. This study found nuanced motivators, such as insights related to addiction and recovery based on previous experiences, whether positive or negative. These might offer clues about countertransference, ways to address and overcome vicarious trauma, and empathy among recovering individuals working in this field. In addition, cross-sectional and longitudinal quantitative research might be useful for measuring the features of recovering counselors' narratives, like the impact of motivation at different points in their careers. For example, suppose they are motivated to help others. In that case, it is important to investigate whether time, experience, or other potential factors such as rewards or challenges altered their motivation to continue working as addiction practitioners. Future macro-level studies can be conducted on staff recruitment and retention, staff schedules, and service hours to address heavy workloads. The importance of social support and self-care to avoid relapse must also be examined.

\section{ACKNOWLEDGEMENT}

Thank you to Professor Subadra Panchanadeswaran, Drs. Berger, Kyriakakis, and Mallow, and the anonymous referees for suggestions on this manuscript.

\section{REFERENCES}

American Psychiatric Association. (2013). Diagnostic and statistical manual of mental disorders (5th ed.). https://doi.org/10.1176/appi. books. 9780890425596

Bathish, R., Best, D., Savic, M., Beckwith, M., Mackenzie, J., \& Lubman, D. I. (2017). "Is it me or should my friends take the credit?" The role of social networks and social identity in recovery from addiction. Journal of Applied Social Psychology, 47(1), 35-46. https://doi. org/10.1111/jasp. 12420

Beraldo, L., Gil, F., Ventriglio, A., de Andrade, A. G., da Silva, A. G., Torales, J., Gonçalves, P. D., Bhugra, D., \& Castaldelli-Maia, J. M. (2019). Spirituality, religiosity and addiction recovery: Current perspectives. Current Drug Research Reviews, 11(1), 26-32. https://doi.org/10.2174/ 1874473711666180612075954

Best, D., Beckwith, M., Haslam, C., Haslam, S. A., Jetten, J., Mawson, E., \& Lubman, D. I. (2016). Overcoming alcohol and other drug addiction as a process of social identity transition: The social identity model of recovery (SIMOR). Addiction Research \& Theory, 24(2), 111-123. https://doi. org/10.3109/16066359.2015.1075980 
Best, D., Bliuc, A. M., Iqbal, M., Upton, K., \& Hodgkins, S. (2018). Mapping social identity change in online networks of addiction recovery. Addiction Research \& Theory, 26(3), 163-173. https://doi.org/10.1080/16066359.20 17.1347258

Bilgin, M. (2015). The investigation of work values on pyschological counseling and guidance students. International Journal of Eurasia Social Sciences, 6(21), 187-198.

Bliuc, A. M., Best, D., Iqbal, M., \& Upton, K. (2017). Building addiction recovery capital through online participation in a recovery community. Social Science \& Medicine, 193, 110-117. https://doi. org/10.1016/j.socscimed.2017.09.050

Bouchery, E., \& Dey, J. (2018). Substance use disorder workforce [Data set]. Mathematica Policy Research.

Braun, V., \& Clarke, V. (2014). What can "thematic analysis" offer health and wellbeing researchers? International Journal of Qualitative Studies on Health and Well-Being, 9(1), Article 26152. https://doi.org/10.3402/qhw.v9.26152

Brown, E. M. (2017). Cross-racial trust factors: Exploring the experiences of blacks who have had white mentors in the counseling profession [Doctoral dissertation, Old Dominion University]. ProQuest Dissertations Publishing.

Bunce, A. E. (2019). “What we're saying makes sense so I've subscribed to it and I try to live by it'. A qualitative exploration of prisoners 'motivation to participate in an innovative rehabilitation programme through the lens of self-determination theory [Doctoral dissertation, University of Surrey]. ProQuest Dissertations Publishing. https://doi.org/10.15126/thesis.00852929

Calcaterra, S. L., Bach, P., Chadi, A., Chadi, N., Kimmel, S. D., Morford, K. L., Roy, P., \& Samet, J. H. (2019). Methadone matters: What the United States can learn from the global effort to treat opioid addiction. Journal of General
Internal Medicine, 34(6), 1039-1042. https://doi. org/10.1007/s11606-018-4801-3

Cheung, C. C. (2016). An exploration of why entering the profession of counseling: The personal choices of university counselors in mainland China [Doctoral dissertation, The Chinese University of Hong Kong]. ProQuest Dissertations Publishing.

Chick, J. (2015). Recovery: Twelve simple steps to life beyond addiction. Alcohol and Alcoholism, 50(1), 103. https://doi.org/10.1093/alcalc/agu086

Chien, E. (2020). Diversity in the genetic counseling profession: Perspectives on barriers and motivations [Master's thesis, Rutgers, The State University of New Jersey]. ProQuest Dissertations Publishing.

Clandinin, D. J., \& Caine, V. (2013). Narrative inquiry. In reviewing qualitative research in the social sciences. Routledge.

Corey, M. S., \& Corey, G. (2020). Becoming a helper. Cengage Learning.

Creswell. J. W. (2007). Qualitative inquiry and research design: Choosing among five approaches. Sage Publications.

Danes, L. (2016). Professional satisfaction and subjective perception of provided services quality in employment counselors. Romanian Journal of Experimental Applied Psychology, 7(2), 82-96.

Deane, F. P., Goff, R. O., Pullman, J., Sommer, J., \& Lim, P. (2019). Changes in mental health providers' recovery attitudes and strengths model implementation following training and supervision. International Journal of Mental Health and Addiction, 17(6), 1417-1431. https:// doi.org/10.1007/s11469-018-9885-9

Deci, E. L., \& Ryan, R. M. (2008). Self-determination theory: A macrotheory of human motivation, development, and health. Canadian Psychology/ Psychologie Canadienne, 49(3), 182-185. https:// doi.apa.org/doi/10.1037/a0012801 
DeLucia, C., Bergman, B. G., Formoso, D., \& Weinberg, L. B. (2015). Recovery in Narcotics Anonymous from the perspectives of long-term members: A qualitative study. Journal of Groups in Addiction \& Recovery, 10(1), 3-22. https://doi. org/10.1080/1556035X.2014.969064

Dermatis, H., \& Galanter, M. (2016). The role of twelve-step-related spirituality in addiction recovery. Journal of Religion and Health, 55(2), 510-521. https://doi.org/10.1007/s10943-0150019-4

Doukas, N. (2015). A contemporary new role for counselors in recovery: Recovery coaches in communities of recovery. Alcoholism Treatment Quarterly, 33(2), 244-247. https://doi.org/10.10 80/07347324.2015.1018786

Doukas, N., \& Cullen, J. (2010). Recovered addicts working in the addiction field: Pitfalls to substance abuse relapse. Drugs: Education, Prevention \& Policy, 17(3), 216-231. https://doi. org/10.3109/09687630802378864

Dugdale, S., Elison, S., Davies, G., Ward, J., \& Dalton, M. (2016). Using the transtheoretical model to explore the impact of peer mentoring on peer mentors' own recovery from substance misuse. Journal of Groups in Addiction \& Recovery, 11(3), 166-181. https://doi.org/10.1080/155603 5X.2016.1177769

DuPont, R. L., Compton, W. M., \& McLellan, A. T. (2015). Five-year recovery: A new standard for assessing effectiveness of substance use disorder treatment. Journal of Substance Abuse Treatment, 58, 1-5. https://doi.org/10.1016/j. jsat.2015.06.024

Farber, B. A., Manevich, I., Metzger, J., \& Saypol, E. (2005). Choosing psychotherapy as a career: Why did we cross that road? Journal of Clinical Psychology, 61(8), 1009-1031. https://doi. org/10.1002/jclp.20174

Fei, J. T. B., Yee, A., Habil, M. H. B., \& Danaee, M. (2016). Effectiveness of methadone maintenance therapy and improvement in quality of life following a decade of implementation. Journal of Substance Abuse Treatment, 69, 50-56. https:// doi.org/10.1016/j.jsat.2016.07.006

Fialk, A. (2018). Wounded versus non-wounded healers and substance abuse treatment: Countertransference considerations. [Doctoral dissertation, Yeshiva University]. ProQuest Dissertations Publishing.

Foss-Kelly, L., \& Protivnak, J. J. (2017). Voices from the desks: Exploring student experiences in counselor education. Journal of Counselor Preparation and Supervision, 9(2), 233263. http://dx.doi.org.libproxy.adelphi. edu/10.7729/92.1181

Gaine, G., Dubue, J., Purdon, S., \& Abba-Aji, A. (2021). The relation between psychological need satisfaction in acute psychiatric hospital and recovery among emerging adults: A selfdetermination theory approach. Psychiatric Rehabilitation Journal, 44(2), 186-196. https:// doi.apa.org/doi/10.1037/prj0000459

Goodman, D. J., Saunders, E. C., \& Wolff, K. B. (2020). In their own words: A qualitative study of factors promoting resilience and recovery among postpartum women with opioid use disorders. BMC Pregnancy and Childbirth, 20(1), 1-10. https://doi.org/10.1186/s12884-020-02872-5

Greene, D. S., Yaffe, J., \& Kopak, A. M. (2019). Relapse among recovering addiction professionals: Prevalence and predictors. Journal of Social Work Practice in the Addictions, 19(4), 323-344. https://doi.org/10.1080/153325 6X.2019.1653718

Gueta, K., Chen, G., \& Ronel, N. (2020). Maintenance of long-term recovery from substance use: A mixed methods study of self-and treatmentchangers. Drugs: Education, Prevention and Policy, 28(5, Special issue), 1-12. https://doi.or g/10.1080/09687637.2020.1800592 
Hatch-Maillette, M. A., Harwick, R., Baer, J. S., Masters, T., Cloud, K., Peavy, M., Wiest, K., Wright, L., Beadnell, B., \& Wells, E. A. (2019). Counselor turnover in substance use disorder treatment research: Observations from one multisite trial. Substance Abuse, 40(2), 214-220. https://doi.org/10.1080/08897077.2019.1572051

Hill, C. E., Lystrup, A., Kline, K., Gebru, N. M., Birchler, J., Palmer, G., Robinson, J., Um, M., Griffin, S., Lipsky, E., \& Knox, S. (2013). Aspiring to become a therapist: Personal strengths and challenges, influences, motivations, and expectations of future psychotherapists. Counselling Psychology Quarterly, 26(3-4), 267-293. https://doi.org/10.1080/09515070.20 13.825763

Kaslow, F. W. (2005). Growing up everyone's trusted confidante: Why I really became a psychotherapist. Journal of Clinical Psychology, 61(8), 965-972. https://doi.org/10.1002/ jclp.20169

Kelly, J. F., Greene, M. C., Bergman, B. G., White, W. L., \& Hoeppner, B. B. (2019). How many recovery attempts does it take to successfully resolve an alcohol or drug problem? Estimates and correlates from a national study of recovering US adults. Alcoholism: Clinical and Experimental Research, 43(7), 1533-1544. https://doi.org/10.1111/acer.14067

Kern, E. O. (2014). The pathologized counselor: Effectively integrating vulnerability and professional identity. Journal of Creativity in Mental Health, 9(2), 304-316. https://doi.org/1 $0.1080 / 15401383.2013 .854189$

Kiang, M. V., Basu, S., Chen, J., \& Alexander, M. J. (2019). Assessment of changes in the geographical distribution of opioid-related mortality across the United States by opioid type, 1999-2016. JAMA Network Open, 2(2), Article e190040. https://doi.org/10.1001/ jamanetworkopen.2019.0040
Lietz, C. A., Langer, C. L., \& Furman, R. (2006). Establishing trustworthiness in qualitative research in social work: Implications from a study regarding spirituality. Qualitative Social Work, 5(4), 441-458. https://doi. org/10.1177/1473325006070288

Linehan, M. M., \& Wilks, C. R. (2015). The course and evolution of dialectical behavior therapy. American Journal of Psychotherapy, 69(2), 97-110. https://doi.org/10.1176/appi. psychotherapy.2015.69.2.97

Linington, M. (2016). The psychotherapist's own psychotherapy: Patient and clinician perspectives. In J. D. Geller \& J. C. Norcross (Eds.), Attachment: New directions in relational psychoanalysis and psychotherapy (pp. 167171). Oxford University Press

Madras, B. K. (2017). The surge of opioid use, addiction, and overdoses: Responsibility and response of the US health care system. JAMA Psychiatry, 74(5), 441-442. https://doi. org/10.1001/jamapsychiatry.2017.0163

Mahrer, A. R. (2005). What inspired me to become a psychotherapist? Journal of Clinical Psychology, 61(8), 957-964. https://doi.org/10.1002/ jclp. 20168

McCullough, M. E. (2000). Forgiveness as human strength: Theory, measurement, and links to well-being. Journal of Social and Clinical Psychology, 19(1), 43-55. https://doi. org/10.1521/jscp.2000.19.1.43

McMillan, D. J., McConnell, B., \& O’Sullivan, H. (2016). Continuing professional developmentwhy bother? Perceptions and motivations of teachers in Ireland. Professional Development in Education, 42(1), 150-167. https://doi.org/10 $.1080 / 19415257.2014 .952044$

Monnat, S. M., Peters, D. J., Berg, M. T., \& Hochstetler, A. (2019). Using census data to understand county-level differences in overall 
drug mortality and opioid-related mortality by opioid type. American Journal of Public Health, 109(8), 1084-1091. https://doi.org/10.2105/ AJPH.2019.305136

Nielson, E. M. (2016). Substance abuse counselors' recovery status and self-schemas: Preliminary implications for empirically supported treatment implementation. Journal of Drug and Alcohol Research, 5, Article 235982. https://doi. org/10.4303/jdar/235982

Norcross, J. C., \& Farber, B. A. (2005). Choosing psychotherapy as a career: Beyond 'I want to help people'. Journal of Clinical Psychology, 61(8), 939-943. https://doi.org/10.1002/jclp.20175

Nowell, B., \& Albrecht, K. (2019). A reviewer's guide to qualitative rigor. Journal of Public Administration Research and Theory, 29(2), 348-363. https://doi.org/10.1093/jopart/muy052

Nurse, R. A. (2020). Case study on perceptions of recovered licensed professional counselors (LPCS) and licensed certified alcohol and drug counselors (LCADC) who counsel co-occurring mentally ill chemical abuser (MICA) [Doctoral dissertation, Capella University]. ProQuest Dissertations Publishing.

Orlinsky, D. E., \& Rønnestad, M. H. (2005). How psychotherapists develop: A study of therapeutic work and professional growth. American Psychological Association.

Ottenberg, D. (1977). Traditional and nontraditional credentials in addictive problems: A dispatch from the battlefield. The Addiction Therapist, 2(1), 56-63.

Patsiopoulos, A. T., \& Buchanan, M. J. (2011). The practice of self-compassion in counseling: A narrative inquiry. Professional Psychology: Research and Practice, 42(4), 301-307. https:// doi.apa.org/doi/10.1037/a0024482

Pietkiewicz, I., \& Skowrońska-Włoch, K. (2017). Attitudes to professional boundaries among therapists with and without substance abuse history. Polish Psychological Bulletin, 48(3), 411-422. https://doi.org/10.1515/ppb-2017-0047

Poon, D. B., Watt, H. M. G., \& Stewart, S. E. (2020). Future counselors' career motivations, perceptions, and aspirations. Higher Education, Skills and Work-Based Learning, 10(1), 155-170. https://doi.org/10.1108/HESWBL-02-2019-0031

Prom-Wormley, E. C., Ebejer, J., Dick, D. M., \&amp; Bowers, M. S. (2017). The genetic epidemiology of substance use disorder: A review. Drug and Alcohol Dependence, 180(1), 241-259. https:// doi.org/10.1016/j.drugalcdep.2017.06.040

Raynor, P. A., Pope, C., York, J., Smith, G., \& Mueller, M. (2017). Exploring self-care and preferred supports for adult parents in recovery from substance use disorders: Qualitative findings from a feasibility study. Issues in Mental Health Nursing, 38(11), 956-963. https://doi.org/10.108 0/01612840.2017.1370520

Reamer, F. G. (2020). Boundary issues and dual relationships in the human services. Columbia University Press.

Renard, M., \& Snelgar, R. J. (2016). How can work be designed to be intrinsically rewarding? Qualitative insights from South African nonprofit employees. South African Journal of Industrial Psychology, 42(1), 1-12. https://doi. org/10.4102/sajip.v42i1.1346

Robinson, S. R. (2018). Mora reasoning and authenticity in paraprofessional and professional and recovering and non-recovering addiction counselors [Doctoral dissertation, University of Holy Cross] ProQuest Dissertations Publishing.

Rønnestad, M. H., \& Skovholt, T. M. (2003). The journey of the counselor and therapist: Research findings and perspectives on professional development. Journal of Career Development, 30(1), 5-44. https://doi. org/10.1177/089484530303000102 
Ruhm, C. J. (2018). Corrected US opioid-involved drug poisoning deaths and mortality rates, 19992015. Addiction, 113(7), 1339-1344. https://doi. org/10.1111/add.14144

Shannon, M. K. (2017). A phenomenological study of female counselors recovering from a substance use disorder [Doctoral dissertation, Capella University]. ProQuest Dissertations Publishing.

Simons, L., Haas, D., Massella, J., Young, J., \& Toth, P. (2017). Exploring professional identity development in alcohol and drug counselors in the 21 st century. Journal of Alcohol and Drug Education, 61(2), 40-61.

Stevanovic, P., \& Rupert, P. A. (2004). Careersustaining behaviors, satisfactions, and stresses of professional psychologists. Psychotherapy: Theory, Research, Practice, Training, 41(3), 301309. https://doi.org/10.1037/0033-3204.41.3.301

Substance Abuse and Mental Health Services Administration. (2018). Key substance use and mental health indicators in the United States: Results from the 2016 National Survey on Drug Use and Health 2017 (No. SMA 17-5044). U.S. Department of Health and Human Services, Center for Behavioral Health Statistics and Quality. https://www.cdc.gov/rdc/data/b1/2018FinalAnalytic-Codebook-RDC508.pdf

Tiesman, H. M., Gwilliam, M., Rojek, J., Hendricks, S., Montgomery, B., \& Alpert, G. (2019). The impact of a crash prevention program in a large law enforcement agency. American Journal of Industrial Medicine, 62(10), 847-858. https:// doi.org/10.1002/ajim.23032

Tracy, K., \& Wallace, S. P. (2016). Benefits of peer support groups in the treatment of addiction. Substance Abuse and Rehabilitation, 7, 143-154. https://doi.org/10.2147/SAR.S81535

Volkow, N. D., Koob, G. F., \& McLellan, A. T. (2016). Neurobiologic advances from the brain disease model of addiction. New England Journal of Medicine, 374(4), 363-371. https:// doi.org/10.1056/nejmra1511480

von Greiff, N., \& Skogens, L. (2021). Recovery and identity: A five-year follow-up of persons treated in 12-step-related programs. Drugs: Education, Prevention and Policy, 28(5), 465-474. https:// doi.org/10.1080/09687637.2021.1909535

Vroom, V. H. (1964). Work and motivation. Wiley \& Sons.

Warren, L., Feit, M. D., \& Wells, J. (2011). Substance abuse among professionals: Limited research on substance-abusing social workers. Journal of Human Behavior in the Social Environment, 21(7), 803-812. https://doi.org/10 $.1080 / 10911359.2011 .616753$

White, W. (2006). Sponsor, recovery coach, addiction counselor: The importance of role clarity and role integrity. Philadelphia Department of Behavioral Health and Mental Retardation Services. http://m.www.williamwhitepapers. com/pr/dlm_uploads/2006-Sponsor-RecoveryCoach-Addiction-Counselor.pdf

Wile, C., \& Jenkins, K. (2013). The value of a support group for medical professionals with substance use disorders. Australasian Psychiatry, 21(5), 481-485. https://doi. org/10.1177/1039856213498289

Yao, C. W., \& Vital, L. M. (2018). Reflexivity in international contexts: Implications for U.S. doctoral students international research preparation. Faculty Publications in Educational Administration, 13, 193-210. https://doi. org/10.28945/4005

Zosky, D. (2013). Wounded healers: Graduate students with histories of trauma in a family violence course. Journal of Teaching in Social Work, 33(3), 239-250. https://doi.org/10.1080/08841 233.2013.795923 